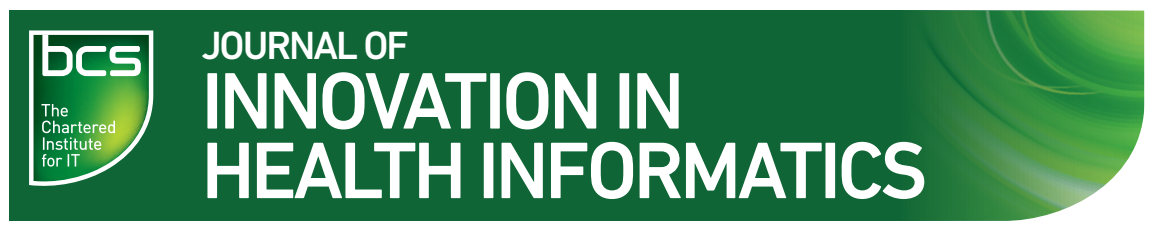

\title{
Miscellaneous
}

Copyright $\odot 2017$ The Author(s). Published by BCS, The Chartered Institute for IT under Creative Commons license http://creativecommons.org/ licenses/by/4.0/

\section{Real-world evidence to an eHealth tool: the 2017 top ten papers from Journal of Innovation in Health Informatics}

\author{
Simon de Lusignan \\ Department of Clinical and Experimental Medicine, University of Surrey, Guildford, UK
}

We celebrate the end of 2017 and the start of 2018 with a review of our top ten papers (Table 1). This is an opportunity to enjoy the papers that are accessed the most - and through them describe to our readers the scope of the journal. Please relish this end of year summary of our work - and consider writing for the journal or commenting on our work through letters, Twitter (@_JoliHi), Linked-in ${ }^{1}$ or building up information about us on Wikipedia. ${ }^{2}$ The aim, scope and ambition for the journal are set out in our 20th Anniversary Issue. ${ }^{3}$ Alongside the presentation of innovative technology, we are looking to promote the development and recognition of our discipline. And, perhaps most challenging of all, the development of its core theory. 4

\section{THE TOP TEN PAPERS}

The top ten papers are chosen based on access statistics that we receive from Crossref $^{5}$; these data were received on 7 November 2017, and they refer to the 12 months up to the end of October. The papers in order of access were as follows:

No. 1. Creating and using real-world evidence (2015)

This paper is a leading article calling on the health community to define what it means by real-world evidence (RWE) and to ensure that its methods are rigorous. ${ }^{6}$ Others have also tried to define what it is and what it is not RWE. ${ }^{7}$ Informaticians, with our understanding of data and health systems, should have a larger part in this debate.

No. 2. Outputs and growth of primary care databases (2017)

Our second most accessed paper focuses on the growth of the use of research databases based on primary care data. ${ }^{8}$ These have had profound growth, and the Clinical Practice Research Datalink (CPRD) was the most used. ${ }^{9}$

\section{No. 3. Phone-based support for Type 1 Diabetes (2005)}

Our next most popular paper described a real-time, mobile phone-based telemedicine system to support young adults with type 1 diabetes. ${ }^{10}$ This is a 2005 paper from the Journal of Informatics in Primary Care and shows that whilst technology moves quickly, issues around implementation are more timeless. 
Table 1 Top 10 articles in 2017 published by - and if primarily a theory or method paper, about the practice or informatics or technology (Tech)

\begin{tabular}{|c|c|c|c|c|c|c|}
\hline Rank & Brief title & Year & $\begin{array}{l}\text { Theoryl } \\
\text { method }\end{array}$ & Practice & Tech & Ref No \\
\hline 1 & Creating and using real-world evidence () & 2015 & $x$ & & & 6 \\
\hline 2 & Outputs and growth of primary care databases & 2017 & & & $x$ & 8 \\
\hline 3 & Phone-based support for type 1 diabetes & 2005 & & & $x$ & 10 \\
\hline 4 & It is like texting at the dinner table & 2017 & & $x$ & & 11 \\
\hline 5 & $\begin{array}{l}\text { Data quality management and information governance } \\
\text { framework }\end{array}$ & 2014 & $x$ & & & 12 \\
\hline 6 & $\begin{array}{l}\text { Web-based portal for physician - business process } \\
\text { is key }\end{array}$ & 2004 & & $x$ & & 13 \\
\hline 7 & $\begin{array}{l}\text { Implementation of an affordable medical record in } \\
\text { Nepal }\end{array}$ & 2017 & & & $x$ & 15 \\
\hline 8 & Reliability of heart rate mobility apps & 2017 & & & $x$ & 16 \\
\hline 9 & $\begin{array}{l}\text { An algorithm to manage data in different brands of } \\
\text { computer system }\end{array}$ & 2016 & $x$ & & & 18 \\
\hline \multirow[t]{5}{*}{10} & Evaluation and analysis of an eHealth tool & 2014 & & & $x$ & 19 \\
\hline & Summary/total & 2017 & & & & \\
\hline & & mode & 3 & 2 & 5 & \\
\hline & & 2015 & & & & \\
\hline & & median & & & & \\
\hline
\end{tabular}

No. 4. It is like texting at the dinner table (2017)

This paper described the experience of hospital patients when their hospital doctor uses their computer during a clinical encounter. ${ }^{11}$ There was a shared feeling they may worsen the quality of the clinical interaction.

\section{No. 5. Data quality management and information governance framework (2014)}

The proposition in this paper is that having good data quality is key to having good governance. ${ }^{12} \mathrm{~A}$ health system, or organisations within it, cannot manage themselves without good-quality data.

\section{No. 6. Web-based portal for physician - business process is key (2004)}

This paper, from well over a decade ago, is in our top ten accessed papers. ${ }^{13}$ Problems about physicians being concerned about being overwhelmed by electronic messages from patients and needing a business process that remunerates them for their time, have remained issues ever since. ${ }^{14}$

\section{No. 7. Implementation of an affordable medical record in Nepal (2017)}

This study describes an affordable medical record system that was set up in Nepal; its lessons could be applied much more widely. ${ }^{15}$

\section{No. 8. Reliability of heart rate mobility apps (2017)}

You might, like your editor, be forgiven for thinking that something as straightforward as measuring heart rate would be reliable between apps. Think again! This paper explained results that might be different ${ }^{16}$ and led your editor to write how you should take nothing for granted in technical innovations in informatics. ${ }^{17}$

No. 9. An algorithm to manage data in different brands of computer systems (2016)

Surprisingly, nationally specified brands of computer systems that use the same coding system - can produce very different answers when the same searches are run! This paper explores the impact on diabetes prevalence of different approaches to recording data in problem orientated compared with episodeorientated computerised medical record systems. It demonstrates that different approaches are needed. ${ }^{18}$

\section{No. 10. Evaluation and analysis of an eHealth tool (2016)}

This study demonstrated the value of using eHealth tools for clinical purposes. The cohort of patients enrolled increased their exercise intensity and duration and achieved an improved symptom score. ${ }^{19}$

\section{Analysis and summary}

Our top ten papers covered all areas of informatics: theory (and methods), practice and technology. Unsurprisingly, $50 \%(5 / 10)$ had a technology focus. The papers spanned 13 years, with three papers being published over 10 years ago. Interestingly, there were none in the top ten published between 2005 and 2013. Our top papers covered four continents, often with international authors; only South America and Africa were not represented.

Our top ten papers give some sense of the scope and breadth of our discipline. They also provide a guide to potential authors about the type of paper we would like to attract, see accessed and cited. 


\section{REFERENCES}

1. Journal of Innovation in Health Informatics. Available from: https://www.linkedin.com/company/9453005/. Accessed 18 December 2017.

2. Journal of Innovation in Health Informatics. Wikipedia. Available from: https://en.wikipedia.org/wiki/Journal_of_Innovation_in_ Health_Informatics. Accessed 18 December 2017.

3. de Lusignan S. Journal of Innovation in Health Informatics: building on the 20-year history of a Health peer review journal. Journal of Innovation in Health Informatics 2015;22(1):152. doi: 10.14236/jhi.v22i1.152.

4. de Lusignan S, Barlow J and Scott P. Genesis of a Faculty of Clinical Informatics at a time of anticipation for some, and ruby, golden and diamond celebrations for others.

5. Crossref. Available from: https://www.crossref.org/. Accessed 18 December 2017).

6. de Lusignan S, Crawford $L$ and Munro N. Creating and using real-world evidence to answer questions about clinical effectiveness. Journal of Innovation in Health Informatics 2015;22(3):368-73. doi: 10.14236/jhi.v22i3.177.

7. Sherman RE, Anderson SA, Dal Pan GJ, Gray GW, Gross $\mathrm{T}$, Hunter NL, et al. Real-world evidence - what is it and what can it tell us? The New England Journal of Medicine 2016;375(23):2293-97.

8. Chaudhry Z, Mannan F, Gibson-White A, Syed U, Ahmed S, Kousoulis $A$, et al. Outputs and growth of primary care databases in the United Kingdom: bibliometric analysis. Journal of Innovation in Health Informatics 2017;24(3):942. doi: 10.14236/ jhi.v24i3.942.

9. Kousoulis AA, Rafi I and de Lusignan S. The and the: building on research success by enhancing benefits for patients and practices. British Journal of General Practice 2015;65(631):5455. doi: 10.3399/bjgp15X683353.

10. Farmer A, Gibson O, Hayton P, Bryden K, Dudley C, Neil A, et al. A real-time, mobile phone-based telemedicine system to support young adults with type 1 diabetes. Informatics in Primary Care 2005;13(3):171-77.

11. Pelland KD, Baier RR and Gardner RL. "It's like texting at the dinner table": a qualitative analysis of the impact of electronic health records on patient-physician interaction in hospitals. Journal of Innovation in Health Informatics 2017;24(2):894. doi: 10.14236/jhi.v24i2.894.

12. Liaw ST, Pearce C, Liyanage $H$, Liaw GS and de Lusignan S. An integrated organisation-wide data quality management and information governance framework: theoretical underpinnings. Informatics in Primary Care 2014;21(4):199-206. doi: 10.14236/jhi.v21i4.87.

13. Kittler AF, Carlson GL, Harris C, Lippincott M, Pizziferri L, Volk LA, et al. Primary care physician attitudes towards using a secure web-based portal designed to facilitate electronic communication with patients. Informatics in Primary Care 2004;12(3):129-38.

14. Mold F and de Lusignan S. Patients' online access to their primary care electronic health records and linked online services: implications for research and practice. Journal of Personalized Medicine 2015;5(4):452-69. doi: 10.3390/jpm5040452.

15. Raut A, Yarbrough C, Singh V, Gauchan B, Citrin D, Verma V, et al. Design and implementation of an affordable, public sector electronic medical record in rural Nepal. Journal of Innovation in Health Informatics 2017;24(2):862. doi: 10.14236/jhi.v24i2.862.

16. Parpinel M, Scherling L, Lazzer S and Della Mea V. Reliability of heart rate mobile apps in young healthy adults: exploratory study and research directions. Journal of Innovation in Health Informatics 2017;24(2):921. doi: 10.14236/jhi.v24i2.921.

17. de Lusignan S. In this issue: innovation in design and implementation in health informatics. Journal of Innovation in Health Informatics 2017;24(2):954. doi: 10.14236/jhi.v24i2.954.

18. de Lusignan S, Liaw, Dedman D, Khunti K, Sadek K and Jones S. An algorithm to improve diagnostic accuracy in diabetes in computerised problem orientated medical records (POMR) compared with an established algorithm developed in episode orientated records (EOMR). Journal of Innovation in Health Informatics 2015;22(2):255-64. doi: 10.14236/jhi.v22i2.79.

19. Tyrrell JS and Redshaw $\mathrm{CH}$. Physical activity in Ankylosing Spondylitis: evaluation and analysis of an eHealth tool. Journal of Innovation in Health Informatics 2016;23(2):169. doi: 10.14236/jhi.v23i2.169. 